\title{
Blockchain-Enabled Trust in Intercompany Networks Applying the Agency Theory
}

\author{
Nick Große \\ Chair of Enterprise Logistics, TU \\ Dortmund University \\ Nick.Grosse@tu-dortmund.de
}

\author{
Tan Gürpinar \\ Chair of Enterprise Logistics, TU \\ Dortmund University \\ Tan.Guerpinar@tu-dortmund.de
}

\author{
Michael Henke \\ Chair of Enterprise Logistics, TU \\ Dortmund University \\ Michael.Henke@tu-dortmund.de
}

\begin{abstract}
Globalization, digitalization and disruptions recently driven by the Covid19 pandemic are affecting today's supply chains and thus are challenging companies in maintaining their businesses. Resulting uncertainties lead to potential over- and undercapacities and therefore to economic inefficiencies in companies. Engaging in intercompany networks can be a way to circumvent inefficiencies by sharing resources via electronic markets. Here, negotiation mechanisms can be used to allocate the exchanged goods tailored to the needs and payment conditions of the network participants. Ensuring trust and enabling cooperation between the participants in such a virtual ecosystem is a major challenge and essential for raising its potentials. Lacks of trust within the single transaction phases impede the negotiation process and in worst case the maintaining of the network. For this reason, Distributed Ledger Technologies (DLT) and their inherent consensus-building functionalities as well as abilities to utilize smart contracts deserve closer investigation. The aim of this paper is to provide a literature review of DLT functionalities coping with behavioral uncertainties, with a closer view on the context of supply chain. The paper examines, to what extend the integration of DLT provides a beneficial contribution to solving trust problems occurring in intercompany negotiations.
\end{abstract}

\section{CCS CONCEPTS}

- Networks; • Network properties; • Network manageability;

\section{KEYWORDS}

Transactions, Distributed Ledger Technology, Confidence, Negotiation, Supply Chain Management

\section{ACM Reference Format:}

Nick Große, Tan Gürpinar, and Michael Henke. 2021. Blockchain-Enabled Trust in Intercompany Networks Applying the Agency Theory. In $20213 r d$ Blockchain and Internet of Things Conference (BIOTC 2021) (BIOTC 2021), July 08-10, 2021, Ho Chi Minh City, Vietnam. ACM, New York, NY, USA, 7 pages. https://doi.org/10.1145/3475992.3475994

\section{INTRODUCTION}

A recent unexpected scarcity in production systems due to outages in the supply chains [1] leads to the question how to cope with

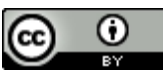

This work is licensed under a Creative Commons Attribution International 4.0 License.

BIOTC 2021, fuly 08-10, 2021, Ho Chi Minh City, Vietnam

(c) 2021 Copyright held by the owner/author(s).

ACM ISBN 978-1-4503-8951-8/21/07.

https://doi.org/10.1145/3475992.3475994 volatile capacity utilization and whether the initial task contingent can be fulfilled by the companies alone or with the help of other companies. For this reason, network concepts receive closer investigation due to their potential in allocating temporary demands within multiple companies [2,3]. Under- and overloads can be efficiently handled via intercompany negotiation, in which unused capacity can be shared for enterprises asking for additional capacity against a fee, independent of the resource which can be a machine capacity [3] or rather a service bundle [4]. A significant amount of market-based approaches emerged during the last years but most of the concepts neglect a closer consideration of solutions to mitigate lacks of trust.

The emergence of cooperations requires trust in the trading partners along the whole transaction process $[5,6]$. On an interorganizational level, trust can be seen as a safeguard that leads to a decrease in both complexity and transaction costs [7, 8]. Due to the fact that trust develops over a long period of time [9], suitable mechanisms need to be found and implemented for creating a sufficient basis for trust-building. For this reason, Distributed Ledger Technologies (DLT) are investigated with regard to transparencyand trust-building functionalities $[10,11]$. However, revealed information are prone to opportunism and exploitation, which impairs the negotiation process and the trust of the participants [5]. At this point, the whole spectrum of behavioral assumptions with regard to the Principal Agent Theory (PA-Theory) are conceivable [12]. The underlying research question in this paper is the following:

Research Question: "To what extent does the integration of DLT mitigate lacks of trust within intercompany negotiation platforms in supply chains?"

The paper is structured as follows. First, fundamentals of networks as coordination structures and their linkage to trust and transaction costs are presented, followed by an introduction to DLT. The main part of the paper is comprised by a systematic literature review. Here, existing literature about DLT integration attempts are gathered with a focus on negotiation processes and analyzed with regard to lacks of trust within intercompany networks. The potentials identified in the literature review are classified into the behavioral assumptions, to which they predominantly contribute to. The findings present a consolidation and emphasis of DLT functionalities contributing to lacks of trust in intercompany networks. The paper is concluded with an emphasis of the most promising DLT functionalities in this context, followed by an outlook, which is pointing out suggestions for further research. 


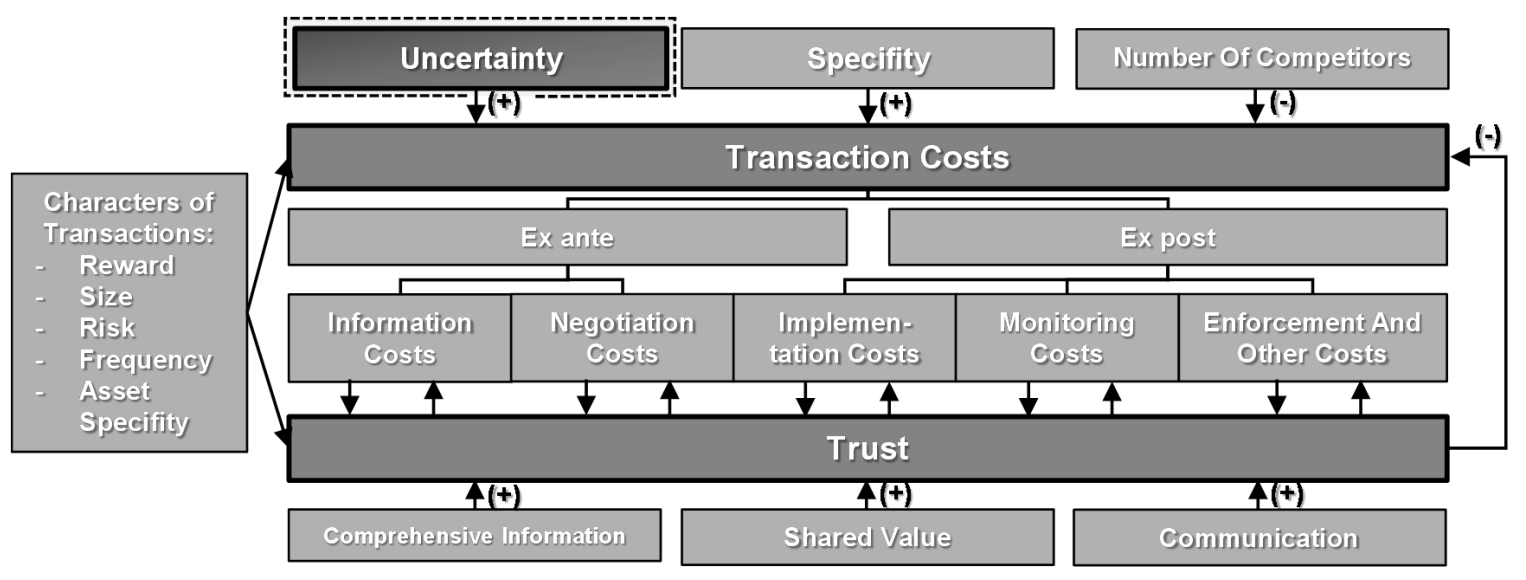

Figure 1: Network of effects between transaction costs and trust (consolidated illustration based on [8, 21]).

\section{BASICS AND FUNDAMENTAL BACKGROUND}

\subsection{Networks, Cooperations, Transactions}

Network coordination structures can be seen as a hybrid form of the dichotomous alternatives 'hierarchy' and 'market' [13, 14]. The relation or rather cooperation of certain companies within a network can be limited by the duration of the negotiation and its corresponding terms of contract, of which [15] gives an example of an arrangement called the 'virtual factory' for production-order limited existence of cooperations. According to [5] a network consists of a plethora of activation potentials, which represent the total amount of possible cooperations, whereas the cooperation itself is the actual use of these activation potentials [5]. Markets are described as the location in which suppliers and customers come together [16]. Enriched by the functionalities of information and communication systems, the negotiations take place in a virtual space, a so-called electronic market [17]. Transactions in (electronic) markets passing through the phases 'information', 'agreement', 'fulfillment' and 'after sales' $[6,18,19]$. According to the time of contract creation, a differentiation can be made into ex ante (before) and ex post (after) transaction stages [18].

\subsection{Uncertainties Induced by Information Assymetry and Trust}

As mentioned in the previous chapter, the intention is to negotiate subcontracts within a network for covering shortcomings. In accordance with the agency theory [12], the bias between the principal and agent caused by information asymmetries can lead to behavioral uncertainties along the whole transaction stages on both before (hidden characteristics) as well as after the contract conclusion (hidden intention and hidden action) among other things due to information asymmetry between the market participants $[8,12,20]$. Following [20], information asymmetry within cooperations can be bypassed by designs such as revealing information (signaling), long-term commitment or (financial) incentives. Besides uncertainty, transaction costs and trust can also be affected by the numbers of competitors within such an ecosystem, the shared value, comprehensibility of the shared information and the possibility of communication [21]. A graphical overview of the mentioned interactions between trust and transaction costs is consolidated from literature and displayed in Figure 1.

\subsection{Distributed Ledger Technologies}

According to [22], DLT can be seen as technologies that allow the utilization of decentralized data repositories, whereas the Blockchain Technology (BCT) is a specific concept of DLT with the special feature of including confirmed transaction blocks inside its repositories [23]. DLT concepts are not necessarily a standalone infrastructure and thus can be applied with existing concepts such as cloud or edge computing [24]. IT solutions based on BCT promise to have a positive effect on trust and could therefore influence transaction costs [11]. The reason lies in several functionalities, such as the cryptographic encryption and distributed storage of data; the use of consensus mechanisms to bring all network participants on one state of truth; the possibility to launch smart contracts to automatize processes; or issue tokens for a peer-to-peer value transfer [25-27].

Past research such as $[10,28]$ emphasize blockchains' contributing effects in terms of building trust in intercompany and marketlike environments and thus motivate for further investigations in concrete use-cases. In this paper, the stated functionalities are projected on the application fields of supply chains considering also adjacent domains. In the following, when speaking of DLT, we will give a focus on BCT. This does not immediately exclude alternative concepts such as Directed Acyclic Graphs (DAG) [29], but due to a lack of maturity in other fields, $\mathrm{BCT}$ receives closer attention.

\section{METHODOLOGY}

In the following, the literature review process as proposed by [30] is used. The approach is commonly used in the area of information systems and disruptive technologies, as e.g. digital twins [31] and also in the fields of blockchain [32]. For this reason, the guidelines are deemed applicable for our research. [30] propose a sequential literature review process, starting with the selection of appropriate sources such as databases, followed by queries through suitable 


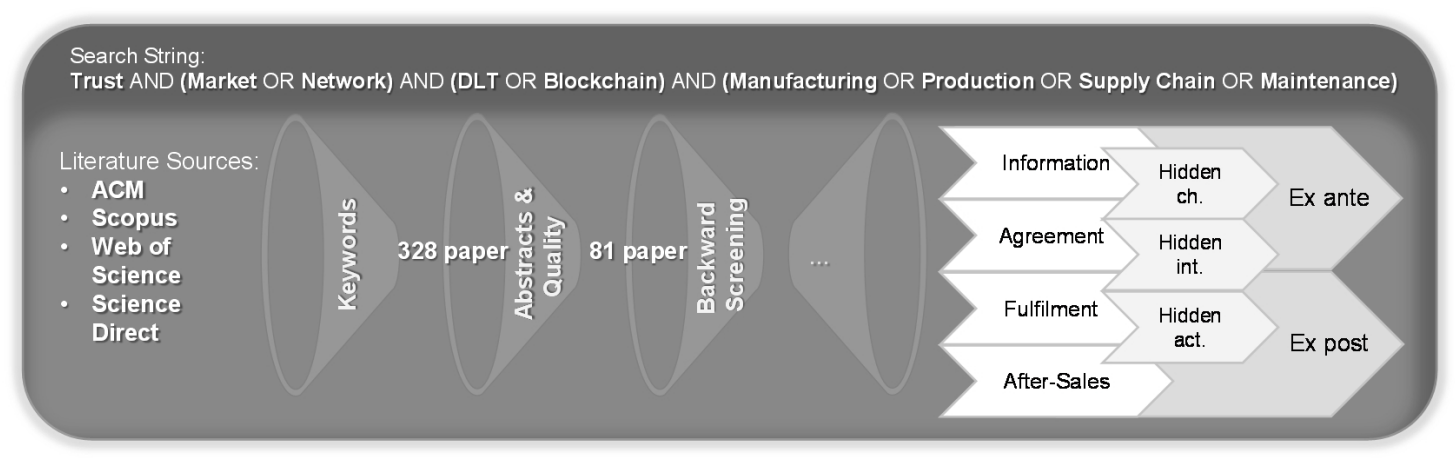

Figure 2: Illustration of the SLR process in accordance with [30]

keywords and a concluding forward and backward analysis. As mentioned in the second chapter of this paper, potential lacks of trust within intercompany networks should be explored via the systematic literature review. Therefore, in a first step, titles, abstracts and keywords are inspected via the databases 'Scopus', 'ACM', 'Web of Science' and 'Science Direct'. The first result undergoes an analysis of relevance solely according to the abstract. The abstracts are subjected to a fine selection according to quality criteria (QC), which excludes too distant topics such as healthcare, agriculture or electricity, whereas topics dealing with topics such as the adoption of the DLT in supply chain networks and sharing economy are included. The composed search string, together with the iterations process is illustrated in Figure 2.

Based on an initial result of 328 paper, the selection process ensures a manageable amount of 81 paper with higher relevance to the given context. Accompanying to the identification and categorization of lacks of trusts mentioned in the selected papers, a short explanation of each transaction phase is given. The objective of the systematic literature review is less in pointing out every paper dealing with lacks of trusts and DLT. Rather, an appropriate number of papers should be selected with the intention to ensure a saturation effect on a comprehensive extent through consolidation.

\section{FINDINGS}

The findings of the literature review are classified into the behavioral assumptions they address. Under the lens of the PA-Theory, blockchain as a concept of DLT can contribute in mitigating uncertainty on both environmental and behavioral uncertainty and thus can help reduce transaction costs [26]. The findings will be categorized into the three general behavioral assumptions of the PA-theory (cf. chapter 2), followed by a projection of five selected functionalities of DLT in mitigating uncertainty across the determined stages.

\subsection{Contributions of DLT Against Hidden Characteristics}

The earliest occurring behavioral assumption concerning opportunistic behavior and information asymmetry is the quality uncertainty or rather hidden characteristic, in which the principal is unsure about the qualification of an agent [20]. Following [20], unveiling and honesty can increase the partners' reputation and thus serve as mitigator for quality uncertainty. Mitigating effects on information asymmetry can be achieved if the agent is revealing more information about himself or herself (signaling) or otherwise by requesting information (screening) [33]. For this reason, DLT functionalities which circumvent information asymmetry in the ex-ante stage (information and negotiation) are in the field of interest.

Smart Contracts: To prevent double spending and thus fraudulent transactions, [25] proposes the utilization of blockchain-based smart contracts, in which capacity can be shared according to the supply chain resource sharing concept without double booking the same resource at the same time.

Distributed Storage: The distributed data storage as a main functionality of BCT ensures the mitigation of a certain degree of information asymmetry and also enables transparency among the supply chain partners and their network [26].

Consensus Mechanisms: To prevent malicious behavior and fraudulent reset of negative reputation by rejoining a network, [27] propose a concept called "trust evaluation system", which is used for managing trust scores within M2M-environments with the help of a trust consensus protocol. [34] propose a concept of a 'bonus point alliance', which consists of a smart contract and the Practical Byzantine Fault Tolerance (PBFT) consensus mechanism in intention to maintain alliance enterprises in distributed networks. The valid source of truth referring to the revealed information, which is validated by consensus mechanisms, can be used as a valid signaling basis for partner selection and thus can reduce the corresponding transaction costs [26].

Cryptographic Mechanisms: To prevent malicious behavior during messaging, digital signatures achieved by public key cryptography and hashing functions can help to ensure that the origin of sent messages cannot be altered and thus enables creditability along the whole supply chain [35]. Furthermore, with the help of access control and consensus mechanisms, only permitted participants can enter the network and write or read data inside a blockchain [25]. These functionalities can be embedded into the early stage of cooperation in which hidden characteristics can be mitigated through these "secured information sharing mechanisms" [25]. Even in cyber-physical-systems in which both humans and machines take decisions, the verification of trusted users is important to prevent opportunistic behavior such as the malicious interception and tampering of data, which can be circumvented 
with an adequate public key infrastructure, certificate authority, consensus mechanisms and immutable timestamps [36].

Tokens: Another concept of coping with malicious behavior can be achieved be the use of tokens, which is exemplary shown by [37] in the fields of tracking carbon emissions via carbon tokens. Furthermore, tokens can be used for security purposes and thus be used to provide a certain amount of users with the permission to get additional access [38], which in turn provides further safeguard for mitigating uncertainties in the ex-ante stage.

Furthermore, BCT provides mitigating effects on both behavioral and environmental uncertainty in so-called "transactional relationships", in the reduction of governance costs and thus transaction costs [26]. A differentiation between trust and reputation mechanism is shown in [39] using the WEB-Peer-To-Peer-file sharing as an example in which the trust depends on reputation to a certain degree and thus affects the willingness of interaction between two peers [39]. To prevent the negative scenario of adverse selection, BCT can help in "dismantling adverse selection effects" and, due to its inherent disintermediation potential, contributes to a reduction of transaction costs [40].

\subsection{Contributions of DLT Against Hidden Intentions}

The second behavioral assumptions occurs during an existing cooperation, in which the agent has the opportunity to reveal his real intention by exploiting gaps in the contract for his own benefit [20]. Quitting the cooperation and new formations are representing sunk or rather hold up costs, which also can be circumvented by safeguards such as reputation, which is represented by the honest favor in the partner network [20].

Smart Contracts: Smart contracts can be used for reducing the degree of human interaction and thus mitigate a source of mistrust [41]. According to [42], smart contract programming languages such as Solidity allows functionalities such as voting, crowdfunding or auctions. [43] propose an approach for auction mechanisms within the Peer-To-Peer-community BlockCom, in which smart contracts can be used as a virtual auctioneer with the aim of maximizing a target key performance indicator such as profit. Smart contracts with their functionality of counteracting against malicious or devious peers therefore represent a trust instance in kind of a middleman and replace common intermediaries [43].

Distributed Storage: The distributed storage ensures that each peer of the network disposes of the same on-chain information status, which cannot be tampered [26]. The inherent transparency and immutability of recorded data can help mitigating occurring problems such as bull-whip effects [41]. Bull-whip effects are one of the core issues in supply chain management that emerge from information asymmetries. Their corresponding bias among supply chain participants can be mitigated by "obtaining an accurate and real-time single-version-of-truth in a trusted transactional base" [41]

Consensus Mechanisms: To achieve integrity and consistency, consensus mechanisms can serve as a safeguard for ensuring unambiguity of the shared data and thus serves as a basis vor distributed trust and consistency of the transactions [44].

Cryptographic Mechanisms: Furthermore, the cryptographic functionality ensures a trustworthy exchange of information, so only selected peers are able to get the information, whereas the encoded information is shared along the whole chain [45]. Reputation mechanisms can be used as an deterrence for opportunistic behavior through its inherent penalties, such as the exploitation of contractual gaps in favor of the agent [20]. Referring to the quality and the retrace of rejected goods, related information can be sustainable storage and a fundament for the evaluation in terms of reputation system [26].

Tokens: [46] proposes a concept, in which tokens are representing consumable resources and indicates the amounts of purchased resources such as material, finished components, consumed energy, time etc. Tracking the consumption amount together with a threshold check, suspicious activities can be traced back to the exceed of a predefined threshold for such tokens. Within a blockchain, mining rewards associated with cryptographic tokens can be used to motivate other peer to accelerate the process of validation and contributes in maintaining the network [47, 48]. Tokens can be used as a proof of origin or so-called "guarantees of origin" [48], which in turn, reflected to the content of our investigation and can be beneficial to proof consistency with regard to the origin of the transaction process.

\subsection{Contributions of DLT Against Moral Hazard}

The third general behavioral assumption within cooperation is taken place at the ex-post stage and is called hidden action or moral hazard [20]. It consists of an uncertainty about the agents' attitude, which can be either traced back to environmental effects or to deliberate opportunistic behavior. Similar to the previously two mentioned behavioral attitudes, moral hazard can be circumvented by safeguards such as reputation [20].

Smart Contracts: [49] present an overview of existing approaches for trust computation, in which different sets of collaboration intrusion detection services can be achieved with the suitable choice of the blockchain type (permissioned, permissionless), consensus mechanism and smart contracts. Smart contracts, as their code is stored in the blockchain, become immutable and their services traceable for ex-post investigations [50].

Distributed Storage: In fact, all records stored on the blockchain offer a continuous proof for malicious behavior without intermediation [50]. Within the supply chain, any suspicious deviation of the initially agreed conditions can be detected by monitoring the recorded information inside the blockchain [51] and thus gives the principal a sustainable evidence for opportunistic behavior. Malicious behavior prevention can be supported by regulatory support achieved with governance rules embedded in the Peer-To-Peer-network [52]. The adoption of BCT in the fields of supply chain leads to a new form of distributed trust, which is beneficial for the prevention of double spending, product loss and thus contributes to compliance [53]. Especially in intercompany networks, BCT provides efforts in the common storing of data, the automatized execution, disintermediation, provenance, business process management and accounting [54]. The combination of immutable timestamps, digital signature and the distributed storage mentioned in [35] a sustainable storage for the post-utilization use of data can be assured. The stored immutable data giving insights 
Table 1: Trust-building beneficials by blockchain functionalities*

\begin{tabular}{|c|c|c|c|}
\hline $\begin{array}{l}\text { Blockchain Functionalities } \\
\text { Behavioral Assumptions }\end{array}$ & $\begin{array}{l}\text { Hidden Characteristics } \\
\text { Quality Uncertainty }\end{array}$ & $\begin{array}{l}\text { Hidden Intention } \\
\text { Holdup }\end{array}$ & $\begin{array}{l}\text { Hidden Action } \\
\text { Moral Hazard }\end{array}$ \\
\hline $\begin{array}{l}\text { Smart } \\
\text { Contracts }\end{array}$ & $\begin{array}{l}\text { Prevention of double spending } \\
\text { activities [25] -> creditability } \\
\text { during information and negotiation } \\
\text { stage }\end{array}$ & $\begin{array}{l}\text { Reduction of intermediaries } \\
\text { leads to a reduction of sources } \\
\text { of mistrust [41] }\end{array}$ & $\begin{array}{l}\text { Allows automated invoice } \\
\text { exchange without a trusted third } \\
\text { party [50] }\end{array}$ \\
\hline $\begin{array}{l}\text { Distributed } \\
\text { Storage }\end{array}$ & $\begin{array}{l}\text { Transparency along supply chain } \\
\text { increases trust in data and thus } \\
\text { reduces transaction costs [58] [26] }\end{array}$ & $\begin{array}{l}\text { Transparency for all peers as } \\
\text { an "real-time } \\
\text { single-version-of-truth" for } \\
\text { coping with bull-whip effects } \\
\text { [41] }\end{array}$ & $\begin{array}{l}\text { Sustainable evidence for } \\
\text { experience reports and } \\
\text { post-documentation as well as } \\
\text { evaluation [35] [51] }\end{array}$ \\
\hline $\begin{array}{l}\text { Consensus } \\
\text { Mechanisms }\end{array}$ & $\begin{array}{l}\text { Confidence in reputation } \\
\text { information through } \\
\text { tamper-proofed confirmations [27] } \\
{[34]}\end{array}$ & $\begin{array}{l}\text { Integrity and consistency of } \\
\text { the transactions can serve as a } \\
\text { valid basis for distributed trust } \\
\text { and prevents its unambiguity } \\
\text { [44] }\end{array}$ & $\begin{array}{l}\text { Decisions to come to consortia } \\
\text { agreements become traceable for } \\
\text { ex-post investigations -> } \\
\text { issuance of certificates or } \\
\text { justification of sanctions [32] }\end{array}$ \\
\hline Cryptographic Mechanisms & $\begin{array}{l}\text { Public key cryptography } \\
\text { architecture can ensure a mutually } \\
\text { agreed insight of shared } \\
\text { information [35] }\end{array}$ & $\begin{array}{l}\text { Prevention of } \\
\text { information-tapping, even } \\
\text { during the cooperation } \\
\text { through access permissions } \\
\text { [45] }\end{array}$ & $\begin{array}{l}\text { Securely hashed information by } \\
\text { strong cryptography -> ex-post } \\
\text { traceability of transactions and } \\
\text { data [51] }\end{array}$ \\
\hline Tokens & $\begin{array}{l}\text { Medium of tracking by } \\
\text { consumption [37]; ex ante } \\
\text { safeguard as a security token with } \\
\text { tamper-proof onboarding [38] }\end{array}$ & $\begin{array}{l}\text { Detecting suspicious behavior } \\
\text { [46]; creditability through } \\
\text { proof of origin [48] }\end{array}$ & $\begin{array}{l}\text { Non-copyable represen-tations } \\
\text { of physical [26] or financial } \\
\text { assets [57] can be traced back to } \\
\text { ownership [56] and thus serves } \\
\text { as a tamper-proof source for } \\
\text { ex-post evaluation. }\end{array}$ \\
\hline
\end{tabular}

${ }^{*}$ Please note that this consolidation is without guarantee of completeness on both functionalities and adoption potentials and initially serves as a first orientation for further discussions. For reasons of scope, only an excerpt of the reviewed literature are considered and listed in the findings.

about the behavior and thus reputation of the opportunistic peer. In a B2B-environment, blockchain provides the functionality of provenance tracking are listed in [54], which in turn can discourage the participants from opportunistic behavior.

Consensus Mechanisms: Apart from the sole blockchainbased consensus mechanisms, [55] provides an overview of alternative consensus mechanisms, which can be adducted, if conditions such as the throughput or the confirmation delay is decisionrelevant e.g. as in the fields of IoT. [51] give an overview of a plethora of functionalities required for IT technologies and IoT applications, especially for the supply chain and thus mentions the requirements of scalability, multiple sources, data sharing, interoperability, identity management, transparency, traceability external interface, payment mechanisms, performance and reliability.

Cryptographic Mechanisms: In the area of cryptographic mechanisms [51] see the needs of privacy and security functionalities in terms of transmission, access control, data provenance and fault detection. Blockchain solutions are seen as a solution able to fulfill these requirements, as they are capable of enabling data- and transaction provenance [51].
Tokens: Tokens can be a way to trace back the ownership [56] of non-copyable assets such as stock coins [57] or digital representations of physical goods and thus its corresponding verified transactions provide a tamper-proof source of ex-post evaluation [26].

\section{CONCLUDING REMARKS AND OUTLOOK}

The performed systematic literature review presents a state of the art of the trust-building potentials of DLT in the field of supply chain. To consolidate the contents theoretically, a classification into the general behavior assumptions has been made, in which the general causes for behavioral uncertainties are mentioned and matched with the functionalities of DLT derived from past research. The findings addressing the answer of this question are subsumed in Table 1. Further investigations in terms of domain-specific use-cases have to be projected on the herein derived solution modules coping with lacks of trust within intercompany cooperation. Furthermore, the problems herein mentioned are only spectated from the lens of PA-Theory and bordering the transaction cost theory. Thus, the findings and conclusions are without guarantee of completeness and also aligned from a market-centric view. The herein mentioned 
compatibility match of DLT functionalities and behavioral assumptions serve as first implications for future work. Moreover, the mitigation of lacks of trust and uncertainty are not the only beneficial effects accompanied by the integration of DLT. For that reason, the consolidated factors of influence can be projected on other economic indicators apart from transaction costs. The findings worked out in this paper can be used as a preliminary basis for decoupling points in terms of case-specific analysis and can also be considered in future designing processes of DLT-based artifacts.

\section{ACKNOWLEDGMENTS}

The work presented in this paper was funded by the Deutsche Forschungsgemeinschaft (DFG) - 276879186/ GRK2193.

\section{REFERENCES}

[1] P. Klink, FAST RAMP-UP: Anlaufmanagement nach disruptiven pandemischen Ereignissen. Whitepaper im Rahmen des For-schungsprojekts "Fast Ramp-Up", Fraunhofer-Gesellschaft, 2020

[2] G. Schuh, Referenzstrategien in einer vernetzten Welt, in: Erfolg in Netzwerken, Springer, 2002, pp. 17-31.

[3] Y. Uygun, A. Kuhn, Integrierte Kapazitätsbörse - Entwicklung eines Instrumentariums für den Handel mit Maschinenkapazitäten in regional-lateralen Unternehmensnetzen. Zugl.: Dortmund, Techn. Univ., Diss., 2012, Verl. Praxiswissen, Dortmund, 2012.

[4] M. Strunz, Instandhaltung: Grundlagen - Strategien - Werkstätten, Springer Vieweg, Berlin, Heidelberg, 2012.

[5] S. Duschek, R. Wetzel, J. Aderhold, Probleme mit dem Netzwerk und Probleme mit dem Management: Ein neu justierter Blick auf relevante Dilemmata und auf Konsequencen für die Steuerung, in: J. Aderhold, M. Meyer, R. Wetzel (Eds.), Modernes Netzwerkmanagement, Gabler Verlag, Wiesbaden, 2005, pp. 143-164

[6] R. Clement, D. Schreiber, Internet-Ökonomie: Grundlagen und Fallbeispiele der vernetzten Wirtschaft, second., vollst. überarb. und erw. Aufl., Springer Gabler, Berlin, 2013.

[7] N. Luhmann, Vertrauen: Ein Mechanismus der Reduktion sozialer Komplexität, fifth. Aufl., UVK-Verl.-Ges; UTB, Konstanz, Stuttgart, 2014.

[8] R. Cai, Trust and transaction costs in industrial districts (2004).

[9] R.J. Lewicki, B.B. Bunker, Trust in relationships: A model of development and decline, Jossey-Bass, 1995.

[10] B. Notheisen, Engineering Decentralized Markets: A Blockchain Approach. Dissertation, Karlsruhe, 2019.

[11] G. Fridgen, N. Guggenberger, T. Hoeren, W. Prinz, N. Urbach, J. Baur, H. Brockmeyer, W. Gräther, E. Rabovskaja, V. Schlatt, A. Schweizer, J. Sedlmeir, L. Wederhake, Chancen und Herausforderungen von DLT (Blockchain) in Mobilität und Logistik, Berlin, 2019.

[12] K.M. Eisenhardt, Agency theory: An assessment and review, Academy of management review 14 (1989) 57-74

[13] O.E. Williamson, Comparative economic organization: The analysis of discrete structural alternatives, Administrative science quarterly (1991) 269-296.

[14] H. Siebert, Ökonomische Analyse von Unternehmensnetzwerken, in: J. Sydow (Ed.), Management von Netzwerkorganisationen, Gabler Verlag, Wiesbaden, 2010, pp. 7-27.

[15] G. Schuh, Management von Unternehmensnetzwerken - Konzepte zur Gestaltung, Lenkung und Entwicklung, in: D. Spath, E. Westkämper, H.-J. Bullinger, H.-J. Warnecke (Eds.), Neue Entwicklungen in der Unternehmensorganisation, Springer Berlin Heidelberg, Berlin, Heidelberg, 2017, pp. 265-282.

[16] R. Steyer, Ökonomische Analyse Elektronischer Märkte, Arbeitspapiere WI (1998) 1-57.

[17] B.F. Schmid, Requirements for electronic markets architecture, Electronic Markets 7 (1997) 3-6.

[18] J. Chen, T. Cai, W. He, L. Chen, G. Zhao, W. Zou, L. Guo, A blockchain-driven supply chain finance application for auto retail industry, Entropy 22 (2020) 95 https://doi.org/10.3390/e22010095.

[19] S. Zumpe, M. Madlberger, A transaction-based framework for business models in electronic commerce, PACIS 2007 Proceedings (2007) 15.

[20] K. Spremann, Asymmetrische information, Zeitschrift für Betriebswirtschaft 60 (1990) 561-586.

[21] J. Lee, J. Kim, J.Y. Moon, What makes Internet users visit cyber stores again? Key design factors for customer loyalty, in: Proceedings of the SIGCHI conference on Human Factors in Computing Systems, 2000, pp. 305-312.

[22] DIN SPEC 3103, Blockchain und Distributed Ledger Technologien in Anwendungsszenarien für Industrie 4.0, Beuth Verlag, Berlin, 2019

[23] C. Diedrich, A. Belyaev, Eisenhardt J., Die Blockchain als eine Technologie für die Verwirklichung von Veisionen der I4.0, Conference: 15. Fachtagung
EKA-Entwurf komplexer Automatisierungssysteme, ifakt/Otto-von-GuerickeUniversität Magdeburg.

[24] N. Große, D. Leisen, T. Gürpinar, R.S. Forsthövel, M. Henke, M. ten Hompel, Evaluation of (De-) Centralized IT technologies in the fields of Cyber-Physical Production Systems, https://doi. org/10.15488/9640 (2020).

[25] T.K. Agrawal, R. Kalaiarasan, M. Wiktorsson, Lalic B., Marjanovic U., Majstorovic V., von Cieminski G., Romero D., Blockchain-Based Secured Collaborative Model for Supply Chain Resource Sharing and Visibility, IFIP Advances in Information and Communication Tech-nology 591 IFIP (2020) 259-266. https://doi.org/10. 1007/978-3-030-57993-7_30.

[26] Christoph G. Schmidt, Stephan M. Wagner, Blockchain and supply chain relations: A transaction cost theory perspective, Journal of Purchasing and Supply Management 25 (2019) 100552. https://doi.org/10.1016/j.pursup.2019.100552.

[27] Besfort Shala, Ulrich Trick, Armin Lehmann, Bogdan Ghita, Stavros Shiaeles, Novel trust consensus protocol and blockchain-based trust evaluation system for M2M application services, Internet of Things 7 (2019) 100058. https://doi.org/10. 1016/j.iot.2019.100058.

[28] Wieninger, Simon (2020): Vertrauen in Unternehmensnetzwerken durch Blockchain-Technologie. Dissertation. Aachen: Apprimus Wissenschaftsverlag.

[29] S. Popov, The tangle, cit. on (2016) 131.

[30] J. vom Brocke, A. Simons, B. Niehaves, B. Niehaves, K. Reimer, R. Plattfaut, A. Cleven, Reconstructing the giant: On the importance of rigour in documenting the literature search process (2009).

[31] H. van der Valk, H. Haße, F. Möller, M. Arbter, J.-L. Henning, B. Otto, A Taxonomy of Digital Twins.

[32] B. Notheisen, F. Hawlitschek, C. Weinhardt, Breaking down the blockchain hypetowards a blockchain market engineering approach (2017).

[33] R. Clement, D. Schreiber, P. Bossauer, C. Pakusch, Internet-Ökonomie, Springer Berlin Heidelberg, Berlin, Heidelberg, 2019.

[34] C. Chen, X. Sun, G. Lu, H. Kang, Y. Shen, Bonus Points Alliance Based on the Block Chain, Proceedings - 2018 14th International Conference on Semantics, Knowledge and Grids, SKG 2018 (2018). https://doi.org/10.1109/SKG.2018.00045.

[35] N. Kawaguchi, Cruz-Cunha M.M., Varajao J.E., Martinho R., Rijo R., Peres E., Domingos D., Application of Blockchain to Supply Chain: Flexible Blockchain Technology, Procedia Computer Science 164 (2019). https://doi.org/10.1016/j. procs.2019.12.166.

[36] A.J.M. Milne, A. Beckmann, P. Kumar, Cyber-Physical Trust Systems Driven by Blockchain, IEEE Access 8 (2020) 66423-66437. https://doi.org/10.1109/ACCESS. 2020.2984675 .

[37] O.W.A. Lam, Z. Lei, Textile and apparel supply chain with distributed ledger technology (DLT), Proceedings - IEEE International Conference on Mobile Data Management 2019-June (2019). https://doi.org/10.1109/MDM.2019.000-4.

[38] R.G. Duran, D. Yarleque-Ruesta, M. Belles-Munoz, A. Jimenez-Viguer, J.L. MunozTapia, An Architecture for Easy Onboarding and Key Life-Cycle Management in Blockchain Applications, IEEE Access 8 (2020) 115005-115016. https://doi.org/10. 1109/AC-CESS.2020.3003995.

[39] Q. Liu, X. Zou, Research on trust mechanism of cooperation innovation with big data processing based on blockchain, Eurasip Journal on Wireless Communications and Networking 2019 (2019). https://doi.org/10.1186/s13638-019-1340-5.

[40] B. Notheisen, J.B. Cholewa, A.P. Shanmugam, Trading Real-World Assets on Blockchain: An Application of Trust-Free Transaction Systems in the Market for Lemons, Business and Information Systems Engineering 59 (2017) 425-440. https://doi.org/10.1007/s12599-017-0499-8.

[41] G.A. Akyuz, G. Gursoy, Transformation of Supply Chain Activities in Blockchain Environment, Contributions to Management Science (2020) 153-175. https://doi. org/10.1007/978-3-030-29739-8_8.

[42] G. Drakopoulos, E. Kafeza, H. Al Katheeri, Proof systems in blockchains: A survey, 2019 4th South-East Europe Design Automation, Computer Engineering, Computer Networks and Social Media Conference, SEEDA-CECNSM 2019 (2019). https://doi.org/10.1109/SEEDA-CECNSM.2019.8908397.

[43] V. Hassija, G. Bansal, V. Chamola, V. Saxena, B. Sikdar, BlockCom: A Blockchain based Commerce Model for Smart Communities using Auction Mechanism, in: 2019 IEEE INTERNATIONAL CONFERENCE ON COMMUNICATIONS WORKSHOPS (ICC WORKSHOPS), 2019.

[44] Hao Xu, Paulo Valente Klaine, Oluwakayode Onireti, Bin Cao, Muhammad Imran, Lei Zhang, Blockchain-enabled resource management and sharing for $6 \mathrm{G}$ communications, Digital Communications and Networks (2020). https://doi.org/ 10.1016/j.dcan.2020.06.002.

[45] S. Makridakis, K. Christodoulou, Blockchain: Current challenges and future prospects/applications, Future Internet 11 (2019). https://doi.org/10.3390/ FI1120258.

[46] N. Teslya, P.A. Abramowicz W., Industrial socio-cyberphysical system's consumables tokenization for smart contracts in blockchain, Lecture Notes in Business Information Processing 339 (2019) 344-355. https://doi.org/10.1007/978-3-03004849-5_31.

[47] Ayşe Kübra Erenoğlu, İbrahim Şengör, Ozan Erdinç, João P.S. Catalão, Chapter 6 - Blockchain and its application fields in both power economy and demand 
side management, in: Miadreza Shafie-khah (Ed.), Blockchain-based Smart Grids, Academic Press, 2020, pp. 103-130.

[48] J.A.F. Castellanos, D. Coll-Mayor, J.A. Notholt, Cryptocurrency as guarantees of origin: Simulating a green certificate market with the Ethereum Blockchain, in 2017 IEEE International Conference on Smart Energy Grid Engineering (SEGE), 2017, pp. 367-372.

[49] W. Meng, E.W. Tischhauser, Q. Wang, Y. Wang, J. Han, When intrusion detection meets blockchain technology: A review, IEEE Access 6 (2018) 10179-10188. https: //doi.org/10.1109/ACCESS.2018.2799854.

[50] D. Kaid, M.M. Eljazzar, Applying Blockchain to Automate Installments Payment between Supply Chain Parties<bold $><$ /bold $>$, in: 2018 14TH INTERNATIONAL COMPUTER ENGINEERING CONFERENCE (ICENCO), 2018, pp. 231-235.

[51] M.S. Ferdous, K. Biswas, M.J.M. Chowdhury, N. Chowdhury, V. Muthukkumarasamy, Kim S., Deka G.C., Zhang P., Integrated platforms for blockchain enablement, Advances in Computers 115 (2019) 41-72. https://doi.org/10.1016/bs. adcom.2019.01.001.

[52] Hayder Albayati, Suk Kyoung Kim, Jae Jeung Rho, Accepting financial transac tions using blockchain technology and cryptocurrency: A customer perspective approach, TECHNOLOGY IN SOCIETY 62 (2020) 101320. https://doi.org/10.1016/ j.techsoc. 2020.101320.

[53] N. Kshetri, E. Loukoianova, Blockchain Adoption in Supply Chain Networks in Asia, IT Professional 21 (2019) 11-15. https://doi.org/10.1109/MITP.2018.2881307.

[54] P. Grover, A.K. Kar, P.V. Ilavarasan, Blockchain for Businesses: A Systematic Literature Review, in: CHALLENGES AND OPPORTUNITIES IN THE DIGITAL ERA, 2018, pp. 325-336.

[55] B. Cao, Y. Li, L. Zhang, S. Mumtaz, Z. Zhou, M. Peng, When Internet of Thing Meets Blockchain: Challenges in Distributed Consensus, IEEE Network (2019). https://doi.org/10.1109/MNET.2019.1900002.

[56] V. Fremont, G.M. Jonathan, Stirna J., Zdravkovic J., Nurcan S., Grabis J., Can blockchain technology solve trust issues in industrial networks?, CEUR Workshop Proceedings 2218 (2018).

[57] E. Hofmann, U.M. Strewe, N. Bosia, Background III-What Is Blockchain Technology?, in: E. Hofmann, U.M. Strewe, N. Bosia (Eds.), Supply Chain Finance and Blockchain Technology, Springer International Publishing, Cham, 2018, pp. 35-49.

[58] P.K. Wan, L. Huang, H. Holtskog, Blockchain-Enabled Information Sharing within a Supply Chain: A Systematic Literature Review, IEEE Access 8 (2020) 4964549656. https://doi.org/10.1109/ACCESS.2020.2980142. 